\title{
Curing Reactions of Bismaleimidodiphenylmethane with Mono- or Di-functional Allylphenols. High Resolution Solid-State ${ }^{13}$ C NMR Study
}

\author{
Sumio Shibahara, Takahisa Yamamoto, ${ }^{*}$ Jiro Motoyoshiya, ${ }^{* *}$ \\ and Sadao HAYASHI $* *$ \\ Kobe Fundamental Research Laboratory, Sumitomo Bakelite Co., Ltd., \\ 1-5 Murotani 1-chome, Nishi-ku, Kobe 651-2241, Japan \\ * Sumibe Techno Research Co., Ltd., 495 Akiba-cho, \\ Totsuka-ku, Yokohama 245-0052, Japan \\ ** Faculty of Textile Science and Technology, Shinshu University, \\ 3-15-1 Tokida, Ueda 386-0018, Japan
}

(Received October 3, 1997)

\begin{abstract}
Analysis of the curing reactions of bismaleimidodiphenylmethane (BMI) with diallylbisphenol-A (DABA) or $o$-allylphenol (AP) with the high resolution solid-state ${ }^{13} \mathrm{C}$ NMR technique revealed that while cured products of BMI and $\mathrm{AP}$ are formed through ene-reaction and the sequential Diels-Alder reaction, no Diels-Alder reaction occurs in the case of DABA and only ene-reaction and polymerization proceed. This shows that the crosslinking of such widely used curing system proceeds via a different manner suggested previously.

KEY WORDS Curing Reaction / Diels-Alder Reaction / ene-Reaction / Bismaleimide / Diallylbisphenol-

A / Solid-State ${ }^{13} \mathrm{C}$ Nuclear Magnetic Resonance /
\end{abstract}

The curing system of bismaleimide has been widely used as thermosetting polyimides, which provides excellent thermal stability but brittleness simultaneously because of the high crosslinking density of the network. In order to add toughness to bismaleimide resins, modification has been made by the addition of diallyl compounds such as diallylbisphenol-A (DABA). ${ }^{1,2}$ The course of this reaction has been investigated and ene- and Diels-Alder reactions were suggested to be involved in this curing system based on the model reaction of $N$ phenylmaleimide (PMI) and $o$-allylphenol (AP) ${ }^{3-5}$ The preceding paper showed that the thermal reaction of PMI and AP gave ene- and Diels-Alder adducts but PMI and DABA did not give the Diels-Alder adduct. ${ }^{6}$ However, the practical curing reaction remains uncertain because the curing products are generally insoluble toward almost of organic solvents, which prevents to characterize the reaction products.

High resolution solid-state NMR with CPMAS (cross polarization magic angle spinning), developed by Schaefer, ${ }^{7}$ has been applied to the analysis of insoluble polymer such as cured thermoset resins. ${ }^{8}$ Our previous studies showed that the solid-state ${ }^{13} \mathrm{C}$ NMR is useful to investigate the curing reactions of bismaleimide resins. ${ }^{9-12}$ Although the solid-state ${ }^{13} \mathrm{C}$ NMR spectrum of the cured product of bismaleimidodiphenylmethane (BMI) with DABA has been illustrated by Carduner et al. ${ }^{13,14}$ detailed descriptions are not available. On the basis of fundamental data of the model reactions, we report in this paper the direct measurements of the curing reactions of BMI and DABA with a high resolution solid-state ${ }^{13} \mathrm{C}$ NMR.

\section{EXPERIMENTAL}

\section{Materials}

BMI, purchased from Wako Pure Chemical Industries, was recrystallized from chloroform-methanol. DABA was obtained from Mitsui Toatsu Chemicals Inc. PMI and $o$-AP were purchased from Wako Pure Chemical Industries.

\section{Sample Preparation}

Mono- or di-functional maleimides and mono- or di-functional allylphenols were mixed in a round bottom flask and heated by an oil bath at $150^{\circ} \mathrm{C}$ for $15 \mathrm{~min}$. Continuous stirring led to a homogenous melt. This mixture was put in a closed aluminous vessel and heated at $175^{\circ} \mathrm{C}$ for $2 \mathrm{~h}$, at $200^{\circ} \mathrm{C}$ for $1 \mathrm{~h}$, and at $250^{\circ} \mathrm{C}$ for $1 \mathrm{~h}$ in an air oven. Each stage samples were analyzed by liquid-state and solid-state ${ }^{13} \mathrm{C}$ NMR.

\section{Liquid-State ${ }^{13}$ C NMR Measurements}

NMR spectra were obtained for samples dissolved in dimethyl- $d_{6}$ sulfoxide (DMSO- $d_{6}$ ) or $\mathrm{CDCl}_{3}$ at room temperature and were recorded on a JEOL JNMGSX400 spectrometer.

\section{Solid-State ${ }^{13}$ C NMR Measurements}

High resolution solid-state ${ }^{13} \mathrm{C}$ NMR spectra, CPMAS spectra, were acquired with a JEOL JNM-EX270W spectrometer equipped with a Doty Scientific CPMAS probe at room temperature. For these measurements, cryoground products were packed into MAS rotors. Sideband interference was eliminated by total suppression of spinning sidebands (TOSS). ${ }^{15}$ Contact time was $2 \mathrm{~ms}$, repetition time $5 \mathrm{~s}$ and spinning rate about $4 \mathrm{kHz}$.

\section{RESULTS AND DISCUSSION}

In the preceding paper, we assigned the products formed from the thermal reaction of PMI and AP with liquid ${ }^{13} \mathrm{C}$ NMR spectral data. ${ }^{6}$ At first, comparison between the liquid and solid state ${ }^{13} \mathrm{C}$ NMR spectra was made. Figure 1 shows their spectra for a reaction mixture of PMI and AP (molar ratio 2/1) treated at $175^{\circ} \mathrm{C}$ 


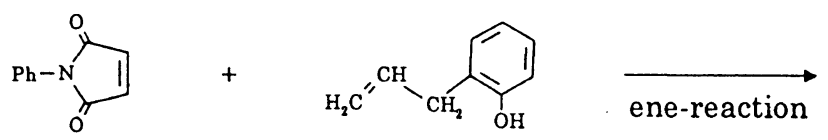

PMI

AP

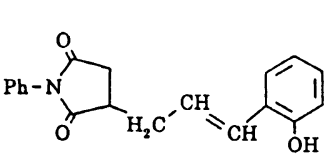

$1: 1$ adduct

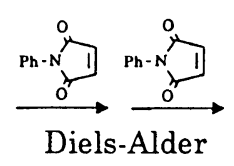

Reactions

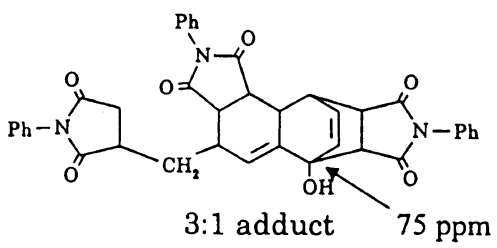

(a)
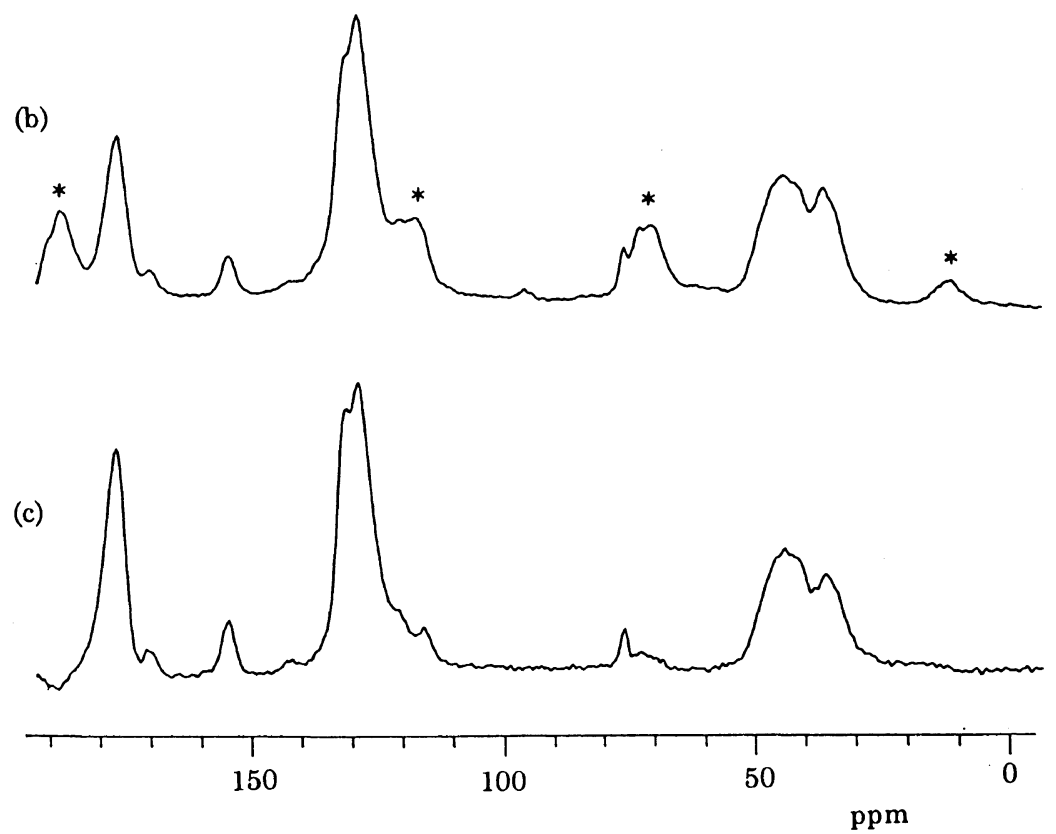

Figure 1. ${ }^{13} \mathrm{C}$ NMR spectra of the reaction products of PMI/AP system treated at $175^{\circ} \mathrm{C}$ for $2 \mathrm{~h}$ : (a) liquid-state NMR spectrum in DMSO- $d_{6}$; (b) CPMAS spectrum (* spinning sidebands); (c) CPMAS spectrum using TOSS.

for $2 \mathrm{~h}$. Solid-state ${ }^{13} \mathrm{C}$ NMR spectra were obtained by CPMAS and spinning sideband interference was eliminated by TOSS. TOSS is clearly of great advantage to distinguish important signals around $75 \mathrm{ppm}$. A signal at $75 \mathrm{ppm}$ ascribed to the $3: 1$ adduct (the Diels-Alder adduct) was observed. Thus, the CPMAS ${ }^{13} \mathrm{C}$ NMR spectra made it possible to analyze the components of the products, taking notice of the signal around $75 \mathrm{ppm}$.

The curing reaction of BMI with DABA (molar ratio 2/1) was carried out under several heating conditions and analyzed by liquid-state ${ }^{13} \mathrm{C}$ NMR and CPMAS ${ }^{13} \mathrm{C}$ NMR as shown in Figure 2. On the basis of fundamental data of the model reactions, ${ }^{6}$ assignments of these spectra were made. The liquid-state ${ }^{13} \mathrm{C}$ NMR spectra of a melt mixture and initial stage of curing (at $175^{\circ} \mathrm{C}$ for $30 \mathrm{~min}$ ) could be measured in DMSO- $d_{6}$, while additional curing products could be monitored only by CPMAS ${ }^{13} \mathrm{C}$ NMR spectra because of insolubility. As observed in the model reaction of PMI and DABA, the ene-adduct was formed after treatment at $175^{\circ} \mathrm{C}$ for $30 \mathrm{~min}$ and assigned from the signals at 176 and $179 \mathrm{ppm}$ (carbonyl carbons), but formation of $3: 1$ adduct was not observed. CPMAS ${ }^{13} \mathrm{C}$ NMR spectra of all stages in the curing reaction showed no distinct signal at $75 \mathrm{ppm}$ in contrast to the model reaction. (A small peak around $70 \mathrm{ppm}$ is the remains of spinning sideband that was not completely removed by TOSS.) The signal at $170 \mathrm{ppm}$ (carbonyl carbon of unreacted BMI), $134 \mathrm{ppm}$ (olefinic carbon of unreacted $\mathrm{BMI}$ ), and $115 \mathrm{ppm}$ (terminal $s p^{2}$ carbon of allyl group) decreased with curing, but the signals at 176, 45, and $30-40 \mathrm{ppm}$ corresponding to carbonyl carbon of reacted BMI, methyne carbon of polymerized BMI, and $s p^{3}$ carbons of polymerized DABA and the ene-product, respectively, increased. Consequently, this curing reac- 


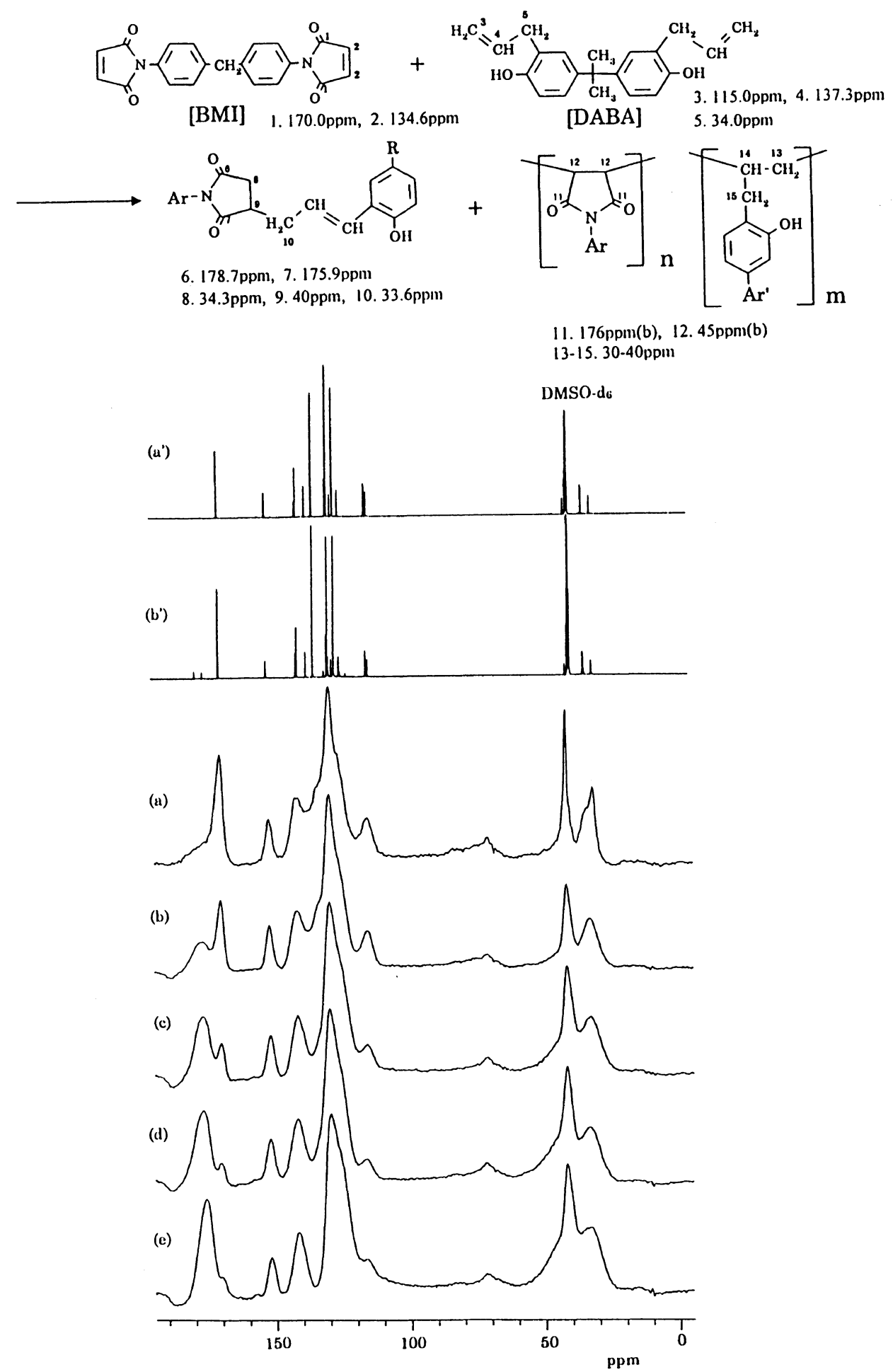

Figure 2. ${ }^{13} \mathrm{C}$ NMR spectra in DMSO- $d_{6}\left(\mathrm{a}^{\prime}, \mathrm{b}^{\prime}\right)$ and CPMAS ${ }^{13} \mathrm{C}$ NMR spectra $(\mathrm{a}-\mathrm{e})$ of the cured products of BMI/DABA system treated at different temperatures: (a) and (a') melt mixture at $150^{\circ} \mathrm{C}$ for $15 \mathrm{~min}$; (b) and (b') at $175^{\circ} \mathrm{C}$ for $30 \mathrm{~min}$; (c) at $175^{\circ} \mathrm{C}$ for $2 \mathrm{~h}$; (d) at $175^{\circ} \mathrm{C}$ for $2 \mathrm{~h}$ and at $200^{\circ} \mathrm{C}$ for $1 \mathrm{~h}$; (e) at $175^{\circ} \mathrm{C}$ for $2 \mathrm{~h}$, at $200^{\circ} \mathrm{C}$ for $1 \mathrm{~h}$, and at $250^{\circ} \mathrm{C}$ for $1 \mathrm{~h}$.

tion produces only the ene-adduct and polymer of BMI and DABA but the Diels-Alder reaction observed in the model reaction does not proceed.

In the CPMAS ${ }^{13} \mathrm{C}$ NMR spectra, signals in the $30-50 \mathrm{ppm}$ region also provided useful information on the products because ${ }^{13} \mathrm{C}$ NMR spectra data of the model reaction showed signals at about $34,35,40 \mathrm{ppm}$ for methylene and methyne carbons ascribed to the ene-adduct and a signal around $45 \mathrm{ppm}$ for methyne carbon of the polymer of maleimides. The broadened signals in this region in Figure 2 indicate that the polymerization of BMI proceeds even at low temperature $\left(175^{\circ} \mathrm{C}\right)$.

To examine differences between the model reaction and the above described curing reaction, thermal reactions of BMI/AP (1/1) and PMI/DABA (4/1) systems were investigated.

Figure 3 shows CPMAS ${ }^{13} \mathrm{C}$ NMR spectra of BMI/AP and PMI/DABA systems treated at several temperatures. In the thermal reaction of $\mathrm{BMI}$ and $\mathrm{AP}$, a signal at 

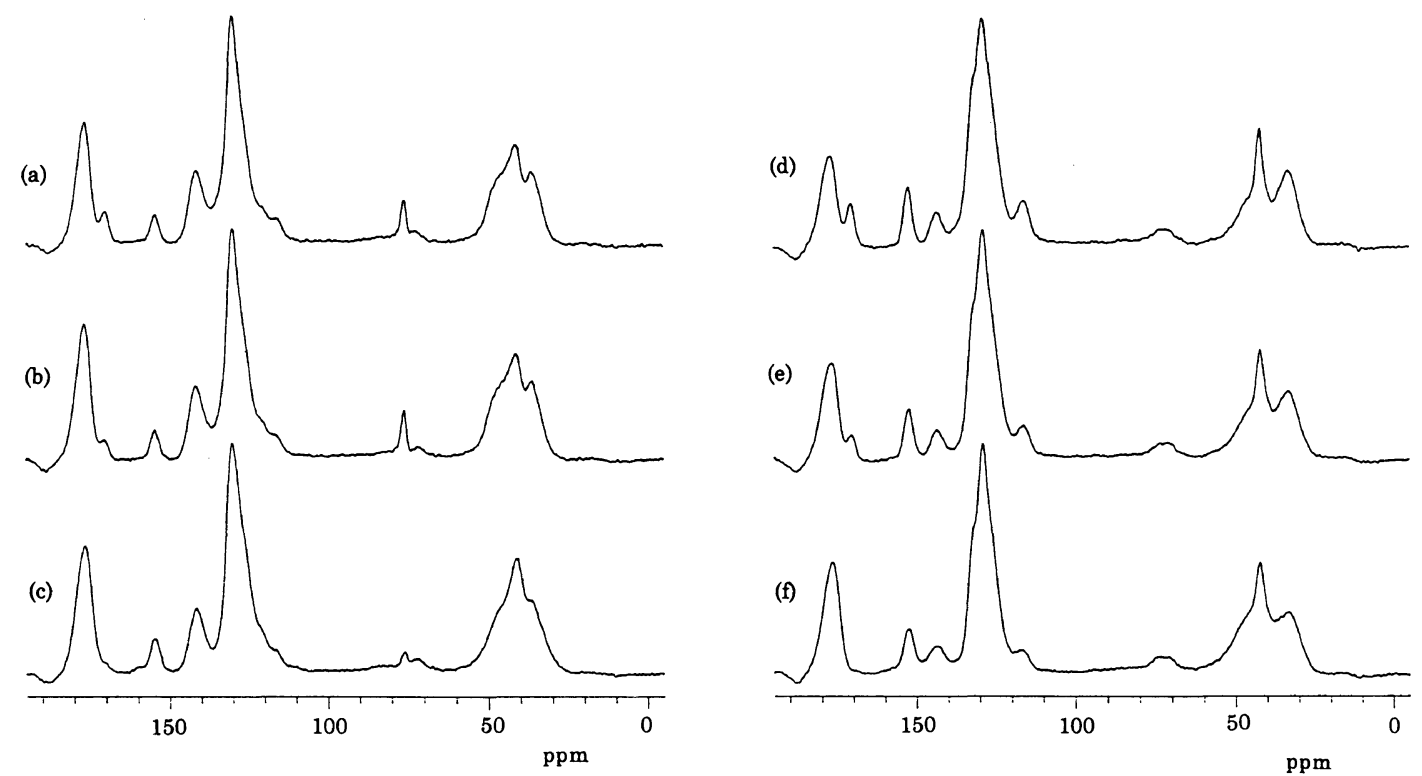

Figure 3. CPMAS ${ }^{13} \mathrm{C}$ NMR spectra of the reaction products of BMI/AP system $(\mathrm{a}-\mathrm{c})$ and PMI/DABA system $(\mathrm{d}-\mathrm{f})$ treated at different temperatures: (a) and (d) at $175^{\circ} \mathrm{C}$ for $2 \mathrm{~h}$; (b) and (e) at $175^{\circ} \mathrm{C}$ for $2 \mathrm{~h}$ and at $200^{\circ} \mathrm{C}$ for $1 \mathrm{~h}$; (c) and (f) at $175^{\circ} \mathrm{C}$ for $2 \mathrm{~h}$, at $200^{\circ} \mathrm{C}$ for $1 \mathrm{~h}$, and at $250^{\circ} \mathrm{C}$ for $1 \mathrm{~h}$.

$75 \mathrm{ppm}$ was observed after heating at $175^{\circ} \mathrm{C}$ similarly to the PMI/AP system (Figures $3 \mathrm{a}-\mathrm{c}$ ). This signal decreased by heating at $250^{\circ} \mathrm{C}$, possibly due to a retro Diels-Alder reaction at this temperature. In the thermal reaction of PMI and DABA, a signal at $75 \mathrm{ppm}$ was not observed similarly to the curing reaction of BMI with DABA (Figures 3d-f).

In the presence of AP, Diels-Alder adducts were formed with both of BMI and PMI, but Diels-Alder reactions hardly proceeded when DABA was used. This leads to conclusion that whether the Diels-Alder reaction proceed or not is dependent on the structures of allylphenols.

\section{CONCLUSION}

This study using high resolution solid-state ${ }^{13} \mathrm{C}$ NMR revealed that the curing reaction of BMI with DABA involved only the ene-reaction and polymerization but the Diels-Alder reaction did not accompany in contrast to the model reaction of PMI and AP. The cured products of BMI with AP formed through ene-reaction and sequential Diels-Alder reaction. This difference between BMI/DABA and BMI/AP was demonstrated only by CPMAS ${ }^{13} \mathrm{C}$ NMR.

\section{REFERENCES}

1. S. Zahir, M. A. Chaudhari, and J. King, Makromol. Chem., Macromol. Symp., 25, 141 (1989).

2. K. A. Barett, M. A. Chaudhari, and B. H. Lee, SAMPE J., 25, 17 (1989).

3. T. Enoki, K. Ishii, H. Okubo, and S. Shibahara, Netsukoukasei Jushi, 12, 9 (1991).

4. T. Enoki, T. Takeda, and K. Ishii, High Perform. Polym., 7, 399 (1995).

5. D. Reyx, I. Campistron, and C. Caillaud, Macromol. Chem. Phys., 196, 775 (1995).

6. S. Shibahara, T. Yamamoto, T. Yamaji, J. Motoyoshiya, and S. Hayashi, Polym. J., 30, 404 (1998).

7. J. Schaefer and E. O. Stejskal, J. Am. Chem. Soc., 98, 103 (1976)

8. S. Tsuge, Netsukoukasei Jushi, 11, 31 (1990).

9. S. Shibahara and T. Enoki, Netsukoukasei Jushi, 11, 87 (1990).

10. S. Shibahara and T. Enoki, Netsukoukasei Jushi, 12, 87 (1991).

11. S. Shibahara, T. Yamamoto, S. Tatsumiya, and M. Miki, Netsukoukasei Jushi, 12, 156 (1992).

12. S. Shibahara, T. Enoki, T. Yamamoto, J. Motoyoshiya, and S. Hayashi, Polym. J., 28, 752 (1996).

13. K. R. Carduner and M. S. Chattha, Polym. Mater. Sci. Eng., 56, 660 (1987).

14. K. R. Carduner and M. S. Chattha, Am. Chem. Soc., Symp. Ser., 367, 379 (1988)

15. W. T. Dixon, J. Schaefer, M. D. Sefick, E. O. Stejskal, and R. A. Mckay, J. Magn. Reson., 49, 345 (1982). 